\title{
Predicting the flow stress of Zircaloy-4 under in-reactor accident conditions
}

DOI:

10.1520/STP159720160075

\section{Document Version}

Accepted author manuscript

Link to publication record in Manchester Research Explorer

\section{Citation for published version (APA):}

Nguyen, C-T., Romero, J., Ambard, A., Preuss, M., \& Quinta Da Fonseca, J. (2018). Predicting the flow stress of Zircaloy-4 under in-reactor accident conditions. In ASTM Proceedings, Zirconium in the Nuclear Industry, 18th International Symposium (Selected Technical Papers). https://doi.org/10.1520/STP159720160075

\section{Published in:}

ASTM Proceedings, Zirconium in the Nuclear Industry, 18th International Symposium

\section{Citing this paper}

Please note that where the full-text provided on Manchester Research Explorer is the Author Accepted Manuscript or Proof version this may differ from the final Published version. If citing, it is advised that you check and use the publisher's definitive version.

\section{General rights}

Copyright and moral rights for the publications made accessible in the Research Explorer are retained by the authors and/or other copyright owners and it is a condition of accessing publications that users recognise and abide by the legal requirements associated with these rights.

\section{Takedown policy}

If you believe that this document breaches copyright please refer to the University of Manchester's Takedown Procedures [http://man.ac.uk/04Y6Bo] or contact uml.scholarlycommunications@manchester.ac.uk providing relevant details, so we can investigate your claim.

\section{OPEN ACCESS}




\title{
Predicting the flow stress of Zircaloy-4 under in-reactor accident conditions
}

\author{
Chi-Toan Nguyen ${ }^{1}$, Javier Romero ${ }^{2}$, Antoine Ambard ${ }^{3}$, Michael Preuss ${ }^{1}$, João Quinta \\ da Fonseca ${ }^{1}$
}

ABSTRACT

During loss of coolant accident (LOCA) and reactivity-initiated accident (RIA), nuclear fuel rods experience high heating rates that change the microstructure and properties of zirconium cladding materials. The aim was to determine how different fast heating rates affect the kinetics of transformation and whether its consequences on the material yield stresses in the dual-phase region could be predicted. Phase fraction and texture of cold-rolled Zircaloy-4 were thus measured at fast heating rates similar to those experienced during LOCA and RIA by in-situ high-energy synchrotron x-ray diffraction; the yield stress was also measured at different heating rates to the same dual-phase temperature by electrical resistance method. Crystal plasticity finite element model was used to simulate the flow stresses with the inputs of the measured phase fraction and texture. The model is calibrated using the flow stress at the heating rate of $10^{\circ} \mathrm{Cs}^{-1}$ and used to predict the flow stress at the heating rate of $50^{\circ} \mathrm{Cs}^{-1}$ at the same temperature. A significant shift of the $\beta$ transus temperature was identified for fast heating rates in the range of $10-100^{\circ} \mathrm{Cs}^{-1}$. There is great similarity in texture at different heating rates. In the dual-phase temperature region, the $\alpha$ texture is almost identical to the starting texture and the $\beta$ texture is nearly random. Yield stresses of cold-rolled Zircaloy-4 decrease at faster heating rate at the same temperature of $920^{\circ} \mathrm{C}$. A good agreement was found between the experimental and predicted flow stress at

\footnotetext{
${ }^{1}$ Materials Performance Centre, The University of Manchester, Manchester M1 7HS, UK

${ }^{2}$ Westinghouse Electric Company, Columbia, South Carolina, US

${ }^{3}$ Electricité de France R\&D, Centre de Renardière, Moret-sur-Loing 77818, France
} 
different heating rates, indicating this methodology has potential to be used to predict flow behavior in a fast transient regime.

\section{KEYWORDS}

Zircaloy-4, yield stress, Loss-of-coolant accident, reactivity-initiated accident, synchrotron X-ray diffraction, kinetics of phase transformation, crystal plasticity

\section{INTRODUCTION}

During LOCA and RIA, the cladding tubes in zirconium alloys heat up rapidly to temperatures in excess of $1000^{\circ} \mathrm{C}$ at the fast rate of 5 to $100^{\circ} \mathrm{Cs}^{-1}$ and are subjected to significant plastic hoop strain and phase transformation from hexagonal close-packed (hcp) $\alpha$ phase to body-centered cubic (bcc) $\beta$ phase [1,2]. The material is then quenched by cool water during re-flooding of the core. Consequently, during LOCA and RIA, the microstructure, crystallographic texture and phase compositions of $\mathrm{Zr}$ alloy cladding develop significantly $[1,2]$.

Fast heating rates above the $\alpha / \alpha+\beta$ transus temperature have been found to cause an increase in the phase transformation temperatures, for example, in Zircaloy-4 [3-6], Zr-Nb alloys $[5,7,8]$ and hydrided Zircaloy-4 [9], and possibly lead to a change in crystallographic texture of each phase during and after the thermal cycles [10-12]. The change in the kinetics of phase transformation and texture could therefore have a significant influence on the mechanical properties of the $\mathrm{Zr}$ cladding materials.

During LOCA and RIA, the Zr cladding tubes are subjected to multi-axial loading, however because of the heating rates involved, it is difficult to fully characterize 
experimentally the yield surface of the material during these transient events. As a consequence, the accuracy of the required engineering analyses is limited.

A methodology is proposed for predicting the flow stress of $\mathrm{Zr}$ cladding materials during LOCA and RIA. This involves determining the effect of heating rate on the phase fraction and texture of both phases and then using this information as an input to a crystal plasticity model, which is calibrated using a test at a known temperature and microstructure. A crystal plasticity model is used since ultimately a yield surface prediction that can account for texture differences is desired. However, in this paper, predictions are only made for uniaxial loading in tension.

The kinetics of phase transformation and texture of cold-rolled Zircaloy-4 was measured at the fast heating rates experienced in LOCA and RIA by synchrotron X-ray diffraction (SXRD). The flow stress of the material under uniaxial tension at the same twophase temperature of $920^{\circ} \mathrm{C}$ at different heating rates of 10 and $50^{\circ} \mathrm{Cs}^{-1}$ was also measured by using electrical resistance method $[13,14]$. The measured flow stress of the cold-rolled Zircaloy-4 at $10^{\circ} \mathrm{Cs}^{-1}$ was then used to calibrate a crystal plasticity model, which was subsequently used to predict the flow stress at a heating rate of $50^{\circ} \mathrm{Cs}^{-1}$. The predicted flow stresses at the rapid heating rates were investigated with different $\beta$-phase fraction and different texture.

\section{EXPERIMENTAL METHODS}

The material studied was Zircaloy-4 sheet supplied by Westinghouse Electric Company in cold-rolled condition with $0.67 \mathrm{~mm}$ thick. The chemical composition of the studied material is shown in Table 1 . The typical microstructure of cold-rolled Zircaloy-4 at room temperature consists of elongated grains in rolling direction (RD), Fig. 1. Rectangular samples for heating and loading experiments were machined by electrical discharge 
machining. They were $2.0 \mathrm{~mm}$ wide in the transverse direction (TD) and $40.0 \mathrm{~mm}$ long along the rolling direction $(\mathrm{RD})$, producing a gauge length of $16.0 \mathrm{~mm}$ for heating and loading experiments on an Instron Electro-Thermo-Mechanical Tester (ETMT), which is a resistive heating stress rig allowing to simultaneously heat by direct current and load.

\section{In-situ Synchrotron x-ray diffraction}

High-energy synchrotron X-ray diffraction (SXRD) was used to measure in-situ phase transformation and texture evolution at fast heating rates at the I12 beamline - the Joint Engineering, Environmental and Processing (JEEP) - at Diamond Light Source, UK. The synchrotron experimental setup was similar to that described by Romero et al. $[10,15]$.

Two samples were measured at the same heating rates with two different directions of the incident beam from normal and transverse direction of the sheet samples, Fig. 2, to improve the pole figure coverage for texture analysis. Debye-Scherrer transmission geometry was employed under a monochromatic beam of $0.1391 \AA(89.13 \mathrm{KeV})$ with the beam size of $500 \mu \mathrm{m} \times 500 \mu \mathrm{m}$. This is much larger than the volume covered in Romero et al. $[10,15]$ in an attempt to achieve better statistics and avoid the grain size and growth issues identified there. A Pixium RF-4343 flat panel detector was selected for full two-dimensional diffraction rings in an active area of $430 \mathrm{~mm} \times 430 \mathrm{~mm}$ with $296 \mu \mathrm{m}$ x $296 \mu \mathrm{m}$ pixel size at the fast acquisition rate of 10 frames per second $(10 \mathrm{~Hz})$. Full diffraction rings were constantly recorded at the rate of $10 \mathrm{~Hz}$ while the samples were heated at different fast heating rates, simulating LOCA/RIA conditions. The material was resistive-heated via controlling direct current at

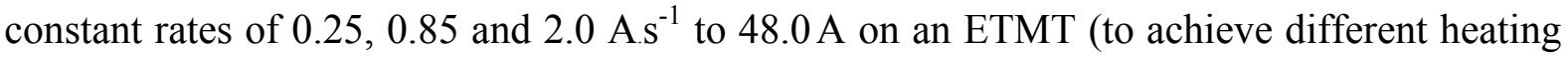
rates of 10,50 and $100^{\circ} \mathrm{Cs}^{-1}$ respectively) to a peak temperature of $1100^{\circ} \mathrm{C}$, holding for 3 seconds before cooling at a rate of $50^{\circ} \mathrm{Cs}^{-1}$, Fig. 3. The thermal cycles were run in air and therefore there could be an effect of oxygen uptake and oxidation on the phase transformation. During heating the load was kept constant at $0.0 \mathrm{~N}$ to allow the material to 
thermally expand freely. The temperature of the samples under constant direct current rates was measured by a R-type $0.15 \mathrm{~mm}$ diameter thermocouple $(\mathrm{Pt} / \mathrm{Pt}-13 \% \mathrm{Rh})$ spot-welded at the mid-length of the heated sample. Due to the water-cooling of the grips on the ETMT, the sample has a parabolic temperature profile along its length and only a small homogenous temperature region up to about $2.0 \mathrm{~mm}$ from the thermocouple at the center $[13,14]$. Therefore all measurements were made in the central area, next to the thermocouple. The welded thermocouple does not seem to affect the measurements [10]. The distance between the samples and the Pixium detector was measured at $1509.385 \mathrm{~mm}$ with a standard $\mathrm{CeO}_{2}$ powder. At the calibrated distance, there are 16 full diffraction rings for $\alpha$ and $6 \beta$-phase rings respectively within a 2 theta range of $2^{\circ}$ to $10^{\circ}$ in the dual-phase region, which are sufficient for structure refinement and phase fraction determination by the Rietveld method.

For phase fraction analysis by SXRD, recorded Debye-Scherrer ring patterns were integrated over the entire azimuthal range by DAWN - Data Analysis WorkbeNch [16], taking into account all the calibration of sample-detector distance, center of the diffraction images and the tilt of Pixium detector. The experimental diffraction spectra of intensity and 2theta at each temperature were then fitted using Rietveld structural refinement as implemented in TOPAS [17].

For texture measurement, two samples with two different directions of incident beam from ND and TD were measured at the same heating rates. Rolling direction of the two samples was along the loading axis of the ETMT load frame. In-situ texture was analyzed in MAUD - Materials Analysis Using Diffraction [10,18-20]. The procedure for texture analysis is described in $[10,15]$. 


\section{Electrical resistance measurement}

\section{Kinetics of phase transformation}

The kinetics of phase transformation of the cold-rolled Zircaloy-4 was also measured by electrical resistance method [21-25] during the in-situ synchrotron diffraction measurements. This was done by measuring the voltage drop between two points $1.0 \mathrm{~mm}$ either side of the center, in a region which is homogenous in temperature $[13,14]$, using spotwelded Pt wires. The electrical resistance at each temperature was then calculated via Ohm's law. The electrical resistivity of cold-worked Zircaloy-4 measured at room temperature over 3 samples is about $683 \mu \Omega . \mathrm{mm}$, which is in very good agreement with that reported in Ref $[26,27]$. The start and end transformation temperatures are assumed to be the temperatures at which the slope of normalized electrical resistance (to that at $300^{\circ} \mathrm{C}$ ) changes when increasing temperature. In other words, phase transformation starts and ends where the first order of derivative of the normalized resistance over temperature is equal to zero, Fig. $4 \mathrm{~b}$. The $\beta$-fraction was then calculated by using an electrical resistivity mixture law of two-phase materials [28]. The resistance of each phase as a function of temperature in the dual phase region was extrapolated using a cubic polynomial for $\alpha$ and a linear function for o [24], Fig. 4a. After that, the $\beta$-fraction in the two extreme cases of parallel and series model, that represent the effect of phase arrangement in dual-phase microstructure, was calculated by the law of mixtures, Fig. 4c. As the values of relative resistance of $\alpha$ and $\beta$ phase are close to each other (less than $20 \%$ difference), the computed values of $\beta$-fraction by series and $\beta$ fraction by parallel model are also very close, and the actual $\beta$-fraction reported is the average of the two. 
The material was heated to $920^{\circ} \mathrm{C}$ by temperature control at the rate of 10 and $50^{\circ} \mathrm{Cs}^{-1}$. When the sample reached a temperature of $920^{\circ} \mathrm{C}$, the material was held for 2 seconds and then stretched, at a cross-head velocity of $0.16 \mathrm{~mm} \cdot \mathrm{s}^{-1}$, to a maximum cross-head displacement of $1.6 \mathrm{~mm}$. The electrical resistance was measured during straining and used for true strain calculation using equation (3) in Roebuck et al. [14]. During the 3 seconds hold time, the electrical resistance shows a slight decrease of less than $3 \%$, Fig. 5b. It means that there is a slight evolution of the $\beta$-phase fraction, which is what we expect. It is limited enough, so that this evolution can be neglected. The $\beta$-phase fraction is therefore assumed to be constant during loading.

As it can be seen in Fig. 5b, there is an increase in resistance during extension that can be used to calculate the reduction in cross-sectional area, from which the axial strain can be inferred. The reduction in cross-sectional area after straining was compared to the strain measured using resistivity showing a difference of less than $7 \%$. The stress and strain curves obtained at $920^{\circ} \mathrm{C}$ at heating rates of 10 and $50^{\circ} \mathrm{Cs}^{-1}$ are shown in Fig. 8. This corresponds to 60 and $30 \% \beta$ fraction respectively, according to the SXRD measurement. All experiments were run in air.

\section{Crystal plasticity finite element modeling}

A crystal plasticity finite element model (CPFEM) was used to predict macroscopic flow stresses under uniaxial tension and deformation behavior of each phase at two-phase temperature of cold-rolled Zircaloy-4. CPFEM can be used for a variety of simulations [29] including the determination of the macroscopic flow stress response and microscopic behavior on load partitioning in multi-phase materials. The CPFE model used here was originally described in Bate [30] and was then employed to predict texture evolution in cold- 
rolling of interstitial free (IF) steel [31], in thermo-mechanical processing of $\beta$-quenched $\mathrm{Zr}$ [32] and intergranular stress of IF steel under uniaxial tension [33]. It uses a small strain formulation and follows the trial stress methodology whereby overall stress equilibrium state is solved at the end of each small strain increment using an elasto-viscoplastic mechanical model.

The material is modeled as a finite element mesh of $10 \times 10 \times 10$ isoparametric brick elements where each grain is presented by an element assigned to a certain phase of $\alpha$ or $\beta$ at random. An element has 20 nodes with 8 integration points. The phase fraction measured by synchrotron X-ray diffraction was assigned over the elements while the crystallographic texture of each phase in the material at performed temperature was applied as a set of orientations to the integration points in each element of the model. The model does not simulate any possible grain boundary relaxation processes. It also does not account for the morphology of each phase and the distribution of each phase in the calculation. The phases are randomly distributed in a FE mesh with a given volume fraction. Each simulation involves 2000 strain increments of $1.0 \times 10^{-4}$ up to a strain of 0.2 . The plane of the face perpendicular to the loading direction, which is the rolling direction of the sheet material, was fixed to provide the necessary boundary conditions for simulating uniaxial tension deformation.

Due to the low activation of twinning in zirconium alloys at high temperature [3436], the CPFE model assumes plastic deformation occurs by slip alone. Slip is assumed to be rate sensitive according to the equation $\frac{\dot{\gamma}}{\dot{\gamma}_{0}}=\left(\frac{\tau}{\tau_{0}}\right)^{\frac{1}{m}}$, where $\dot{\gamma}$ is the instant slip rate, $\dot{\gamma}_{0}$ is a nominal reference slip rate, $\tau$ is the resolved shear stress, $\tau_{0}$ is the instantaneous slip resistance in any given slip system and $m$ is the rate sensitivity and typically equal to 0.02 for 
all slip systems [32,33]. The slip systems considered in the two-phase simulation at high temperature for $\alpha$ phase Zircaloy -4 are prismatic $<\mathrm{a}>$ slip, basal $<\mathrm{a}>\operatorname{slip}$ and pyramidal $<\mathrm{c}+$ a $>$ slip while those for the $\beta$ phase are $\{110\}<111>,\{112\}<111>$ and $\{123\}<111>$ slip. Slip hardening behavior is modeled by using a modified Voce type law, which describes a power law decay of the hardening rate from an initial to a final rate, $\Theta=\Theta_{I V}+\Theta_{0}\left[\left|1-\frac{\tau}{\tau_{s}}\right|^{\alpha} \operatorname{sgn}\left(1-\frac{\tau}{\tau_{s}}\right)\right]$, where $\Theta_{0}$ is the initial hardening rate, $\Theta_{I V}$ is the final hardening rate, $\tau$ is the resolved shear stress and $\tau_{s}$ is a saturation slip resistance and $\alpha$ defines the shape of the stress-strain curve during the transition stage from elastic to plastic behavior.

The single crystal elastic compliances, Table 2, of $\alpha$-phase were obtained from literature [37] while those of $\beta$-phase were initially assumed to be equal to those of $\alpha$ and then calibrated by obtaining a good fit between the experimental data and the simulation. The self and latent hardening are assumed to be unity for all the simulations. The hardening parameters were calibrated manually and the simulation were recalculated until the best fit of the experimental stress-strain response was obtained. The hardening parameters used for each slip system in $\alpha$ and $\beta$ phase at $920^{\circ} \mathrm{C}$ after a heating rate of $10^{\circ} \mathrm{Cs}^{-1}$ are reported in Table 3 . The resultant macroscopic stress-strain curve was obtained by averaging the axial stresses and strains from the CPFEM calculation over all the elements.

The experimental stress-strain curve of cold-rolled Zircaloy- 4 at $920^{\circ} \mathrm{C}$ and at heating rate of $10^{\circ} \mathrm{Cs}^{-1}$, Fig. 8, was used to identify the constitutive parameters of each phase for the CPFE model. The identified parameters were then implemented to the model to predict the flow stresses at a different heating rate, with a different phase fraction and texture as determined by SXRD. The predicted stress-strain curve corresponding to deformation at $920^{\circ} \mathrm{C}$ after heating at $50^{\circ} \mathrm{Cs}^{-1}$ was then compared to that obtained experimentally. The influence of texture on the yield stresses at different heating rates was also investigated by 
comparing the predicted stress-strain curves using the measured textures and using a random texture.

\section{RESULTS}

\section{Kinetics of phase transformation of cold-rolled Zircaloy-4 at fast heating rates}

Fig. 6 shows the measured $\beta$ fraction of cold-rolled Zircaloy-4 by synchrotron X-ray diffraction and electrical resistance at the heating rates of 10,50 and $100^{\circ} \mathrm{Cs}^{-1}$. Both experimental methods show that fast heating rate results in a delay in phase transformation and then a decrease in $\beta$-fraction at a given temperature. There is generally good agreement in $\beta$-fraction measured by SXRD and electrical resistance method. However, the SXRD measurements always show some amount of retained $\alpha$, even after the transformation should have completed. The amount of retained $\alpha$ is higher at lower heating rates. This discrepancy can be attributed to the stabilized $\alpha$ at high temperature due to oxygen uptake on the surface of the sample. This is discussed further later.

\section{Texture evolution during fast heating cycles}

The pole figures of the cold-rolled Zircaloy-4 at room temperature measured by SXRD, shown in Fig. 7, show a strong component in around ND of 0002 pole figure and spread of $11-20$ poles in RD and in $30^{\circ}$ from TD to RD. The cold-rolled texture is consistent with that reported in Tenckhoff [38] and Romero et al. [10].

There is great similarity in the texture components of the material at different heating rates from 10 to $100^{\circ} \mathrm{Cs}^{-1}$ with only slight differences in the texture intensity. Hence, only the texture corresponding to a heating rate of $10^{\circ} \mathrm{Cs}^{-1}$ is shown here. The $\alpha$-texture at $920^{\circ} \mathrm{C}$ consists of strong (0002) basal poles in ND and a spread of 11-20 poles from RD to TD with a strong alignment in RD. The evolution of $\alpha$-texture from room temperature to dual-phase 
temperature suggests that the recrystallization and/or grain growth of $\alpha$-phase occur but are not complete as fully recrystallized texture reported in the Ref. [10,38], where a split of (0002) poles and a rotation of $11-20$ in $\mathrm{RD}$. The texture of $\beta$-phase is essentially random. Further analysis of the texture evolution of each phase and possible variant selection mechanism during phase transformation is beyond the scope of this paper and will be presented elsewhere. The texture of each phase in Fig. 7b was used as an input for the CPFE model.

\section{Experimental flow stress in dual-phase temperature of cold-rolled Zircaloy-4}

The stress-strain curves measured at $920^{\circ} \mathrm{C}$ at the two different heating rates of 10 and $50^{\circ} \mathrm{Cs}^{-1}$ are shown in Fig. 8. Both curves show similar behavior: softening quickly after yielding and deforming at a steady stress up to 0.15 of true strain before softening again up to the final applied strain. At this temperature, the yield and flow stresses of the material are higher after the slower heating rate. Since after a heating rate of 10 and $50^{\circ} \mathrm{Cs}^{-1}$ the material should contain 60 and $30 \%$ of $\beta$-phase, respectively, the change in the strength of the material at different heating rates and at the same temperature is possibly related to the difference in $\beta$ content. If so this implies that the $\beta$ phase is harder than the $\alpha$ phase at this temperature.

\section{DISCUSSION}

\section{Kinetics of phase transformation of cold-rolled Zircaloy-4 at fast heating rates}

Both the SXRD and resistance method measurements show that increasing the heating rate in the range of 10 to $100^{\circ} \mathrm{Cs}^{-1}$ increases the transition temperature and lowers the $\beta$ phase fraction at a given temperature. There is a small difference in $\beta$ phase fraction determined by SXRD and resistance method at high $\beta$-fraction above $90 \%$. This is associated with the stabilized $\alpha$ phase due to oxygen uptake during heating in air. The thickness of stabilized $\alpha$ phase after the heating cycles is shown in Fig. 9 and Table 3. It is clearly larger for slow 
heating rate than that for fast heating rate. The amount of stabilized $\alpha$ phase fraction here is relevant to the un-transformed amount of $\alpha$ phase fraction in SXRD measurements. However, the un-transformed $\alpha$ was not detected in electrical resistance method because of the assumption that the complete transition temperature is at which the overall resistance increases again when increasing temperature. At this point the amount of $\beta$ phase is assumed to be $100 \%$ even though there is a fraction of remaining stabilized $\alpha$ phase.

These data are also compared to those of others in Fig. 6. At a heating rate of $10^{\circ} \mathrm{Cs}^{-1}$, $\beta$-fraction measured by SXRD and resistance are in agreement up to $60 \%$ of $\beta$ to that of Sell and Ortlieb [6] who used the same technique of SXRD with longer exposure time. However, at high temperature about 80 and $100 \% \beta$, the results seem to be different probably because their measurements were done at a longer acquisition rate and in a protected atmosphere. Furthermore, the temperatures at low $\beta$ phase fraction are consistent with those in Forgeron et al. [5] and Brachet et al. [9] at $10^{\circ} \mathrm{Cs}^{-1}$. However, there is a more significant difference at high $\beta$ phase fraction. The difference in the rate growth of transformed $\beta$ between these studies and the present paper could due to a possible discrepancy in starting metallurgical states and possible change in texture during heating before transformation. They used dilatometry to measure the phase fraction, the results of which could be influenced by changes in microstructure and texture via a difference in anisotropic thermal expansion [39]. Although it is clear from the texture evolution that the recrystallization starts, we did some ex-situ observation of the microstructure, texture and misorientation profile of the cold-rolled Zircaloy-4 after heating at 10 to $100^{\circ} \mathrm{Cs}^{-1}$ to before transformation temperature, e.g. $900^{\circ} \mathrm{C}$, revealed the non-equiaxed grains with much varied size, suggesting that the recrystallization is not complete. Therefore, the difference in metallurgical states, which possibly occurs due to fast heating rates before transformation, could lead to the difference in the rate growth of $\beta$ 
during phase transformation and eventually the disagreement at high $\% \beta$ of the Ref. $[5,9]$ and the present measurements.

\section{Prediction of flow stresses by crystal plasticity finite element model}

The stress strain curve of cold-rolled Zircaloy- 4 at $920^{\circ} \mathrm{C}$ after a heating rate of $50^{\circ} \mathrm{Cs}^{-}$

${ }^{1}$ was simulated in a crystal plasticity finite element model (CPFEM) from the calibration at the heating rate of $10^{\circ} \mathrm{Cs}^{-1}$. Fig. 10 shows the fit between the experimental and calibrated flow stress at $920^{\circ} \mathrm{C}$ for the heating rate of $10^{\circ} \mathrm{Cs}^{-1}$ with $60 \% \beta$ although the softening of the material right after yielding cannot be captured. This upper yield point might be related to the presence of a $\alpha$-case. This was not taken into account in the CPFEM. The calibration process provides a set of single crystal and hardening parameters at the experimental temperature of $920^{\circ} \mathrm{C}$ that can be used to predict the flow stress after different heating rates.

Fig. 11 shows a comparison between the experimental flow stress at $920^{\circ} \mathrm{C}$ after a heating rate of $50^{\circ} \mathrm{Cs}^{-1}$ and the predicted flow curve at the same temperature using measured phase fraction and texture at $50^{\circ} \mathrm{Cs}^{-1}$. As it can be seen in Fig. 11 there is good agreement between the experimental and predicted flow stress at $50^{\circ} \mathrm{Cs}^{-1}$. This indicates it might indeed be possible to use phase fraction and texture data to predict the flow stress in these materials during a LOCA or RIA event.

Fig. 12 shows the effect of texture on the predicted flow stress and compares it with the effect of phase fraction. It shows that the effect of texture on the flow stress is much smaller than that of $\beta$ phase fraction. The small effect of texture on the predicted yield stress is due to the weak texture of $\beta$ phase and the small ratio (1.6) of critical resolved shear stresses for $<\mathrm{a}>$ slip and $<\mathrm{c}+\mathrm{a}>$ slip of $\alpha$ phase used in the model. In future, in-situ loading experiments will be used to determine this ratio experimentally. 
Fig. 13 shows the calibrated and predicted mean stresses in each phase of cold-rolled Zircaloy-4 at $920^{\circ} \mathrm{C}$ for the heating rate of 10 and $50^{\circ} \mathrm{Cs}^{-1}$ respectively. The model predicts that the $\beta$ phase is stronger than $\alpha$.

It is well known that as the temperature increases, the flow stress of the material decreases, e.g [40]. Garde et al. [40] attributed this decrease to the increase of $\beta$ fraction with temperature, implying that the $\beta$ phase is weaker in the dual phase regime. However, the decrease in the flow stress is expected because as the temperature increases the strength of both $\alpha$ and $\beta$ is expected to decrease. Therefore, a decrease in the flow stress with temperature does not necessarily imply that the $\beta$ is weaker, even though the $\beta$ phase fraction is higher. The effect of temperature cannot usually be separated from $\beta$-phase fraction, but using high heating rates this becomes to be possible. Our results show that, when this is achieved, the material with more $\beta$-fraction is actually stronger.

If the $\beta$ phase is stronger, the increase in yield stress at slower heating rates can be reasonably associated with the increase of the $\beta$-phase fraction. At room temperature and in dual-phase $\mathrm{Zr}-\mathrm{Nb}$ materials, it was suggested that the higher strength of $\beta$ may be due to the segregation of alloying elements, e.g. $\mathrm{Nb}$, with a contribution from its fine grain size [41]. Further study [42] by the same authors on deformation of $\mathrm{Zr}-\mathrm{Nb}$ alloys at room temperature with higher $\beta$-phase fraction shows an increase in strength of the $\alpha$ phase which is stronger than $\beta$ phase in these conditions. This was attributed to (1) the increase of $O$ content in their studied alloys due to solid strengthening mechanism and to (2) the grain size refinement of $\alpha$ phase due to increasing $\mathrm{Nb}$-content. However, at high temperature and in our studied Zircaloy-4, it seems there is almost no element segregation due to low solubility of the alloying elements in the material content. Oxygen content is similar from the same materials. Therefore, the effect of element segregation and oxygen hardening is likely not the case. The higher strength of $\beta$ could be due to a finer $\beta$ grain size at higher heating rate. The growth of 
$\beta$ phase from its $\alpha$ grain boundaries appears to be limited at high heating rates, resulting in higher nucleation rates and a smaller $\beta$ grain size. Another possibility of an increase in strength of Zircaloy-4 at slower heating rates could be the effect of Sn diffusion. In fact, Sn is an $\alpha$-stabilizer and likely diffuses out of $\beta$ phase to $\alpha$ phase at high temperature and hence strengthens the $\alpha$ phase, similar to the increase in strength of Zircaloy-4 at higher Sn contents [43]. Hence, it is possibly that the increase in yield stress at slower heating rate is due to an increase in strength of $\alpha$ phase due to more diffusion of $\mathrm{Sn}$ at slower heating rate. Therefore, future studies using in-situ synchrotron x-ray diffraction will measure the in-situ intergranular lattice elastic strain of each phase during straining and provide more data on the relative strength of each phase, e.g. which of $\alpha$ and $\beta$ is deforming more. Measurements at Diamond Light Source to better calibrate the single crystal elastic constants and hardening parameters of each phase have already been planned.

The model assumes that the $\beta$ phase fraction does not change during straining for about 12 seconds at the fast heating rate at the same temperature. This assumption is reasonable since during the 2 -second hold before straining, the electrical resistance at the fast heating rate slightly decreases about $3 \%$. This implies that the growth of $\beta$ phase at constant temperature is slow. Since the straining ends after 12 seconds, the constant $\beta$ fraction assumption holds. Slow transformation kinetics has been seen previously in $\mathrm{Zr}-1 \% \mathrm{Nb}$ during a 2 hour heat treatment at $900^{\circ} \mathrm{C}$ after heating at $10^{\circ} \mathrm{Cs}^{-1}$ to two-phase temperature [5]. However, although this can be explained by the slow diffusion of $\mathrm{Nb}$, there is no $\mathrm{Nb}$ or equivalent in Zircalloy-4, so the effect observed here might be driven by the microstructure. This effect will also be tested by synchrotron X-ray diffraction by repeating phase fraction measurements during a more complex heating profile with a change in heating rate within two-phase region. 
The methodology proposed is able to successfully predict flow stresses of cold-rolled Zircaloy-4 under uniaxial tensile tests in rolling direction from a given heating rate to another. Since the methodology uses a crystal plasticity framework, it is straightforward to use the model to define a complete yield surface. However, it is important to first calibrate the material parameters better, in particular to ensure that the single crystal anisotropy of $\alpha$ is well captured, since it will have the biggest effect on the anisotropy of the material.

\section{CONCLUSIONS}

High-energy synchrotron X-ray diffraction was used to measured the kinetics of phase transformation and texture of cold-rolled Zircaloy-4 at fast heating rates in LOCA/RIA conditions. Increasing the heating rate in the range typical of LOCA/RIA events delays the transformation. Therefore, at a given temperature, material heated more slowly contains a higher volume fraction of $\beta$.

In the dual-phase temperature region, the $\alpha$ texture is almost identical to the starting texture and the $\beta$ texture is nearly random.

At $920^{\circ} \mathrm{C}$, the flow stress is higher after a lower heating rate, when the $\beta$-fraction is higher. The relative strength of each phase should be analyzed further to confirm whether the increase in flow stress at lower heating rate relates to the higher $\beta$-fraction or stronger $\alpha$ phase likely due to Sn diffusion.

The increase in yield stress of the material with decreasing heating rate can be predicted using a crystal plasticity finite element model, calibrated at a different heating rate but using the correct $\beta$ volume fraction. Initial simulation suggests that accounting for $\beta$ volume fraction is more important than accounting for texture.

The complete route from implementing measured experimental data on phase fraction and texture to validate flow stresses in a crystal finite model illustrates the ability to predict 
the yield surface of $\mathrm{Zr}$ cladding materials under in-reactor accidental conditions of LOCA and RIA.

\section{ACKNOWLEDGEMENTS}

The authors would like to thank Électricité de France and Westinghouse Electric Company for supporting the work. The help of the beamline scientist Robert Atwood of I12 at Diamond Light Source is gratefully acknowledged. 


\section{REFERENCES}

[1] F. Erbacher, S. Leistikow, Zircaloy fuel cladding behavior in a loss-of-coolant accident: A review, in: R.B. Adamson, L.F.P. Van Swam (Eds.), Zircon. Nucl. Ind. Seventh Int. Symp. Vol. ASTM STP, ASTM International, Philadelphia, 1987: pp. 451-488.

[2] H. Chung, Fuel Behavior under Loss-of-Coolant Accident Situations, Nucl. Eng. Technol. 37 (2005) 327-362.

[3] A. Miquet, D. Charquet, C.H. Allibert, Solide state phase equilibria of Zircaloy-4 in the temperature range $750-1050^{\circ} \mathrm{C}$, J. Nucl. Mater. 105 (1982) 132-141.

[4] T. Terai, Y. Takahashi, S. Masumura, T. Yoneoka, Heat capacity and phase transition of Zircaloy-4, J. Nucl. Mater. 247 (1997) 222-226.

[5] T. Forgeron, J. Brachet, F. Barcelo, A. Castaing, J. Hivroz, P. Mardon, et al., Experiment and modeling of advanced fuel rod cladding behavior under LOCA conditions: Alpha-beta phase transformation kinetics and EDGAR methodology, in: G.. Sabol, G.. Moan (Eds.), Zircon. Nucl. Ind. Twelfth Int. Symp. ASTM STP 1354, ASTM International, West Conshohocken, PA, 2000: pp. 256-278.

[6] H.J. Sell, E. Ortlieb, Effects of Alpha-Beta Transformation on High Temperature (LOCA) Creep behavior of Zr-Alloys, in: G. Moan, P. Rudling (Eds.), Zircon. Nucl. Ind. Thirteen. Int. Symp., ASTM International, West Conshohocken, PA, 2002: pp. 658-672. doi:10.1520/STP1423-EB.

[7] O. Beneš, P. Van Uffelen, J. Van de Laar, C. Győri, R.J.M. Konings, Z. Hózer, Kinetic studies of the $\alpha-\beta$ phase transition in the $\mathrm{Zr} 1 \% \mathrm{Nb}$ cladding for nuclear reactors, J. Nucl. Mater. 414 (2011) 88-91. doi:10.1016/j.jnucmat.2010.12.034.

[8] Z. Hózer, E. Perez-Feró, T. Novotny, I. Nagy, M. Horvath, A. Pinter-Csodas, et al., Experimental comparison of the behavior of E110 and E110G claddings at high temperature, in: R. Comstock, P. Barberis (Eds.), Zircon. Nucl. Ind. 17th Int. Symp. STP 1543, ASTM International, West Conshohocken, PA, 2015: pp. 932-951. doi:10.1520/STP154320120165.

[9] J. Brachet, L. Portier, T. Forgeron, Influence of hydrogen content on the $\alpha / \beta$ phase transformation temperatures and on the thermal-mechanical behavior of $\mathrm{Zy}-4$, M4 (ZrSnFeV), and M5 (ZrNbO) alloys, in: G. Moan, P. Rudling (Eds.), Zircon. Nucl. Ind. Thirteen. Int. Symp. ASTM STP 1423, ASTM International, West Conshohocken, PA, 2002: pp. 673-701.

[10] J. Romero, M. Preuss, J. Quinta da Fonseca, Texture memory and variant selection during phase transformation of a zirconium alloy, Acta Mater. 57 (2009) 5501-5511. doi:10.1016/j.actamat.2009.07.046. 
[11] M.R. Daymond, R.A. Holt, S. Cai, P. Mosbrucker, S.C. Vogel, Texture inheritance and variant selection through an hcp-bcc-hcp phase transformation, Acta Mater. 58 (2010) 4053-4066. doi:10.1016/j.actamat.2010.03.012.

[12] N. Gey, M. Humbert, Characterization of the variant selection occurring during the $\alpha \rightarrow \beta \rightarrow \alpha$ phase transformations of a cold rolled titanium sheet, Acta Mater. 50 (2002) 277-287. doi:10.1016/S1359-6454(01)00351-2.

[13] B. Roebuck, J.D. Lord, L.P. Orkney, Validation of a Miniature Tensile Strength Measurement System, in: M.A. Sokolov, J.D. Landes, G.E. Lucas (Eds.), Small Specim. Test Tech. Fourth Vol. ASTMSTP 1418, ASTM International, West Conshohocken, PA, 2002: pp. 234-250.

[14] B. Roebuck, D.C. Cox, R.C. Reed, An Innovative Device for the Mechanical Testing of Miniature Specimens of Superalloys, Superalloys 2004 (Tenth Int. Symp. (2004) 523-528. doi:10.7449/2004/Superalloys_2004_523_528.

[15] J. Romero, M. Preuss, J. Quinta da Fonseca, Capturing the texture changes in a zirconium alloy during the allotropic phase transformation, Scr. Mater. 61 (2009) 399402. doi:10.1016/j.scriptamat.2009.04.031.

[16] M. Basham, J. Filik, M.T. Wharmby, P.C.Y. Chang, B. El Kassaby, M. Gerring, et al., Data Analysis WorkbeNch (DAWN), J. Synchrotron Radiat. 22 (2015) 853-858. doi:10.1107/S1600577515002283.

[17] Bruker, TOPAS, Version 4.2, Bruker AXS, Karlsruhe, Ger. (2009).

[18] L. Lutterotti, S. Matthies, H.-R. Wenk, a. S. Schultz, J.W. Richardson, Combined texture and structure analysis of deformed limestone from time-of-flight neutron diffraction spectra, J. Appl. Phys. 81 (1997) 594. doi:10.1063/1.364220.

[19] G. Ischia, H.-R. Wenk, L. Lutterotti, F. Berberich, Quantitative Rietveld texture analysis of zirconium from single synchrotron diffraction images, J. Appl. Crystallogr. 38 (2005) 377-380. doi:10.1107/S0021889805006059.

[20] J. Romero, M. Preuss, J. Quinta da Fonseca, R.J. Comstock, M. Dahlbäck, L. Hallstadius, et al., Texture Evolution of Zircaloy-2 During Beta-Quenching: Effect of Process Variables, J. ASTM Int. 7 (2010) 176-194. doi:10.1520/JAI103014.

[21] G. Hörz, M. Hammel, H. Kanbach, Electrical resistivity of $\beta$-Zirconium-oxygen solid solutions as a function of oxygen concentration and temperature, J. Nucl. Mater. 55 (1975) 291-298.

[22] M. Corchia, F. Righini, Kinetic aspects of the phase transformations in Zircaloy-2, J. Nucl. Mater. 97 (1981) 137-148.

[23] D. Arias, R.C. Guerra, Phase Transition Temperature in Zircaloy 2, J. Nucl. Mater. 144 (1987) 196-199. 
[24] M. Canay, C.A. Dan, D. Arias, Phase transition temperature in the Zr-rich corner of Zr $\pm \mathrm{Nb} \pm \mathrm{Sn} \pm \mathrm{Fe}$ alloys, J. Nucl. Mater. 280 (2000) 365-371.

[25] D. Kaddour, S. Frechinet, A.F. Gourgues, J.C. Brachet, L. Portier, A. Pineau, Experimental determination of creep properties of Zirconium alloys together with phase transformation, Scr. Mater. 51 (2004) 515-519.

doi:10.1016/j.scriptamat.2004.05.046.

[26] C.L. Whitmarsh, Review of Zircaloy-2 and Zircaloy-4 Properties Relevant to N.S. Savannah Reactor Design, Tennessee, 1962.

[27] J. Schemel, ASTM manual on zirconium and hafnium, ASTM International, 1977.

[28] Z. Fan, A new approach to the electrical resistivity of two-phase composites, Acta Metall. Mater. 43 (1995) 43-49.

[29] F. Roters, P. Eisenlohr, L. Hantcherli, D.D. Tjahjanto, T.R. Bieler, D. Raabe, Overview of constitutive laws, kinematics, homogenization and multiscale methods in crystal plasticity finite-element modeling: Theory, experiments, applications, Acta Mater. 58 (2010) 1152-1211. doi:10.1016/j.actamat.2009.10.058.

[30] P. Bate, Modelling deformation microstructure with the crystal plasticity finiteelement method, Philos. Trans. R. Soc. A Math. Phys. Eng. Sci. 357 (1999) 15891601. doi:10.1098/rsta.1999.0391.

[31] P.S. Bate, J. Quinta da Fonseca, Texture development in the cold rolling of IF steel, Mater. Sci. Eng. A. 380 (2004) 365-377.

[32] D. Leo Prakash, M. Preuss, M. Dahlback, J. Quinta da Fonseca, Microstructure and texture evolution during thermomechanical processing of $\beta$-quenched $\mathrm{Zr}$, Acta Mater. 88 (2015) 389-401. doi:10.1016/j.actamat.2014.12.033.

[33] J. Quinta da Fonseca, E.C. Oliver, P.S. Bate, P.J. Withers, Evolution of intergranular stresses during in situ straining of IF steel with different grain sizes, Mater. Sci. Eng. A. 437 (2006) 26-32. doi:10.1016/j.msea.2006.04.057.

[34] A. Akhtar, A. Teghtsoonian, Plastic deformation of Zirconium single crystal, Acta Metall. 19 (1971) 655-663.

[35] I.J. Beyerlein, C.N. Tomé, A dislocation-based constitutive law for pure Zr including temperature effects, Int. J. Plast. 24 (2008) 867-895. doi:10.1016/j.ijplas.2007.07.017.

[36] M. Preuss, J.Q. da Fonseca, V. Allen, D.G.L. Prakash, M.R. Daymond, Twinning in structural material with a hexagonal close-packed crystal structure, J. Strain Anal. Eng. Des. 45 (2010) 377-390. doi:10.1243/03093247JSA624.

[37] E.S. Fisher, C.J. Renken, Single-Crystal Elastic Moduli and the hcp $\rightarrow$ bcc transformation in Ti, Zr and Hf, Phys. Rev. 135 (1964) 482-494. 
[38] E. Tenckhoff, Review of deformation mechanisms, texture, and mechanical anisotropy in zirconium and zirconium base alloys, J. ASTM Int. 2 (2005) 1-77.

[39] J.C. Brachet, J.L. Béchade, A. Castaing, L. Le Blanc, T. Jouen, Relationship between Crystallographic Texture and Dilatometric Behaviour of a Hexagonal Polycrystalline Material, Mater. Sci. Forum. 273-275 (1998) 529-534. doi:10.4028/www.scientific.net/MSF.273-275.529.

[40] A. Garde, Strain aging in $\alpha$-Zirconium and $\alpha$-Zircaloy at 1000K, J. Nucl. Mater. 80 (1979) 195-206.

[41] S. Cai, M.R. Daymond, R.A. Holt, Modeling the room temperature deformation of a two-phase zirconium alloy, Acta Mater. 57 (2009) 407-419. doi:10.1016/j.actamat.2008.09.020.

[42] S. Cai, M.R. Daymond, R.A. Holt, Deformation of high $\beta$-phase fraction $\mathrm{Zr}-\mathrm{Nb}$ alloys at room temperature, Acta Mater. 60 (2012) 3355-3369.

doi:10.1016/j.actamat.2012.02.040.

[43] K. V. Mani Krishna, D.G. Leo Prakash, G. Timar, A. Fitzner, D. Srivastava, N. Saibaba, et al., The effect of loading direction and Sn alloying on the deformation modes of Zr: An in-situ neutron diffraction study, Mater. Sci. Eng. A. 650 (2016) 497509. doi:10.1016/j.msea.2015.10.047. 


\section{LIST OF TABLE CAPTIONS}

\begin{tabular}{cccccc}
\hline Zircaloy-4 & $\mathrm{Zr}$ & $\mathrm{Sn}$ & $\mathrm{Fe}$ & $\mathrm{Cr}$ & $\mathrm{O}$ \\
\hline$\% w t$ & Balance & 1.24 & 0.17 & 0.1 & 0.12 \\
\hline
\end{tabular}

Table 1: Chemical composition of Zircaloy-4

\begin{tabular}{ccccccc}
\hline$\left(10^{-5} \times \mathrm{MPa}^{-1}\right)$ & $\mathrm{S}_{11}$ & $\mathrm{~S}_{12}$ & $\mathrm{~S}_{13}$ & $\mathrm{~S}_{33}$ & $\mathrm{~S}_{44}$ & $\mathrm{~S}_{66}$ \\
\hline$\alpha$ & 2.623 & -1.481 & -0.373 & 1.085 & 4.975 & 8.929 \\
$\beta$ & 3.097 & -1.366 & - & - & 4.975 & - \\
\hline
\end{tabular}

Table 2: Single crystal elastic compliance constants of $\alpha$ [37] and $\beta$ phases of coldrolled Zircaloy-4 at $920^{\circ} \mathrm{C}$

\begin{tabular}{cccccccc}
\hline CPFEM & Slip Systems & $\theta_{0}$ & $\theta_{\mathrm{IV}}$ & $\alpha$ & $\begin{array}{c}\tau_{\mathrm{s}} \\
(\mathrm{MPa})\end{array}$ & $\begin{array}{c}\tau_{0} \\
(\mathrm{MPa})\end{array}$ & $\mathrm{m}$ \\
\hline Prismatic & 0.001 & 0.50 & 3.0 & 15.0 & 5.0 & 0.02 \\
Basal & 0.001 & 0.50 & 3.0 & 15.0 & 5.0 & 0.02 \\
& Pyramidal $<\mathrm{c}+\mathrm{a}>$ & 0.001 & 0.50 & 3.0 & 30.0 & 8.0 & 0.02 \\
\hline$\{110\}<111>$ & 0.001 & 0.50 & 1.37 & 17.0 & 7.0 & 0.02 \\
& $\{112\}<111>$ & 0.001 & 0.50 & 1.37 & 17.0 & 7.0 & 0.02 \\
$\{123\}<111>$ & 0.001 & 0.50 & 1.37 & 17.0 & 7.0 & 0.02 \\
\hline
\end{tabular}

Table 3: Hardening parameters of $\alpha$ and $\beta$ phase calibrated at $920^{\circ} \mathrm{C}$ at $10^{\circ} \mathrm{Cs}^{-1}$ in of cold-rolled Zircaloy-4

\begin{tabular}{cccc}
\hline $\begin{array}{c}\text { Heating rate } \\
\left({ }^{\circ} \mathrm{Cs}^{-1}\right)\end{array}$ & $\begin{array}{c}\text { Stabilized } \alpha \\
\text { thickness }(\mu \mathrm{m})\end{array}$ & $\begin{array}{c}\text { \% } \alpha \text { remained by } \\
\text { stabilized- } \alpha\end{array}$ & $\begin{array}{c}\text { \% remained by } \\
\text { SXRD }\end{array}$ \\
\hline 10 & $22.30 \pm 0.69$ & 6.65 & 8.79 \\
50 & $8.52 \pm 0.36$ & 2.54 & 4.44 \\
100 & $7.38 \pm 0.27$ & 2.17 & 3.70 \\
\hline
\end{tabular}

Table 4: Stabilized $\alpha$ thickness and calculated $\% \alpha$ remained by stabilized $\alpha$ at room temperature and by SXRD measurement after fast thermal cycles at different heating rates in cold-rolled Zircaloy-4 with $670 \mu \mathrm{m}$ thick 


\section{LIST OF FIGURE CAPTIONS}

Fig. 1: Optical micrograph of cold-rolled Zircaloy-4

Fig. 2: High-energy synchrotron experimental setups with 2 directions of incident beam from normal direction (ND) and transverse direction (TD).

Fig. 3: Direct current controlled at constant rates of $0.25,0.85$ and $2 \mathrm{As}^{-1}$ by the ETMT to achieve the fast heating rates of 10,50 and $100^{\circ} \mathrm{Cs}^{-1}$ respectively on cold-rolled Zircaloy-4 samples of $16.0 \mathrm{~mm} \times 2.0 \mathrm{~mm} \times 0.67 \mathrm{~mm}$ dimension, after controlling temperature at $200^{\circ} \mathrm{C}$ at the same heating of $5^{\circ} \mathrm{Cs}^{-1}$.

Fig. 4: (a) Measured normalized electrical resistance to that of $300^{\circ} \mathrm{C}$ at each temperature on a cold-rolled Zircaloy-4 at $100^{\circ} \mathrm{Cs}^{-1}$ on an ETMT. (b) The first derivative of the normalized resistance to temperature. (c) $\beta$-fraction estimated by the two extreme cases of resistance [28].

Fig. 5: (a) Evolution of sample temperature and direct current under temperature control at $10^{\circ} \mathrm{Cs}^{-1}$ up to $920^{\circ} \mathrm{C}$ before straining on an ETMT; (b) Evolution of electrical resistance under ETMT cross-head movements of $1.6 \mathrm{~mm}$ at the velocity of $0.16 \mathrm{mms}^{-1}$.

Fig. 6: $\beta$-approach curves of cold-rolled Zircaloy-4 at fast heating rates of 10, 50 and $100^{\circ} \mathrm{Cs}^{-1}$ measured by synchrotron $\mathrm{x}$-ray diffraction (SXRD) and electrical resistance method on 2 samples each, showing less sampling variability. The $\beta$-fractions are compared to those of Zircaloy-4 in the literature at relevant heating rates $[5,6,9]$.

Fig. 7: Pole figures of cold-rolled Zircaloy-4 (a) at room temperature and (b) at $920^{\circ} \mathrm{C}$ at $10^{\circ} \mathrm{Cs}^{-1}-30 \% \beta$ measured by SXRD. 
Fig. 8: Experimental flow stresses of cold-rolled Zircaloy-4 at $920^{\circ} \mathrm{C}$ at 10 and $50^{\circ} \mathrm{Cs}^{-}$ ${ }^{1}$ with ETMT cross-head expansion of $1.6 \mathrm{~mm}$ at the rate of $0.16 \mathrm{~mm} \mathrm{~s}^{-1}$, measured by electrical resistance.

Fig. 9: Optical micrographs of cold-rolled Zircaloy-4 after the heating cycles at (a) $10^{\circ} \mathrm{Cs}^{-1}$, (b) $50^{\circ} \mathrm{Cs}^{-1}$ and (c) $100 \mathrm{Cs}^{-1}$, revealing more un-transformed $\alpha$-case due to oxygen uptake and oxidation at slower heating rates.

Fig. 10: Calibrated single crystal and hardening parameters for the CPFE model of cold-rolled Zircaloy- 4 at $920^{\circ} \mathrm{C}$ at $10^{\circ} \mathrm{Cs}^{-1}$ by fitting experimental and predicted flow stresses which is taken into account the measured texture and phase fraction in this condition.

Fig 11: Comparison between the experimental macroscopic flow stress of cold-rolled Zircaloy-4 at $920^{\circ} \mathrm{C}$ at $50^{\circ} \mathrm{Cs}^{-1}$ and the predicted flow stress at the same temperature by CPFEM with measured phase fraction and texture by SXRD.

Fig. 12: Effect of phase fraction and texture on predicted flow stress of cold-rolled Zircaloy-4 at $920^{\circ} \mathrm{C}$ by CPFEM.

Fig. 13: Predicted flow stresses of each phase of cold-rolled Zircaloy-4 at $920^{\circ} \mathrm{C}$ at the heating rate of (a) $10^{\circ} \mathrm{Cs}^{-1}-60 \% \beta$ and (b) $50^{\circ} \mathrm{Cs}^{-1}-30 \% \beta$. 


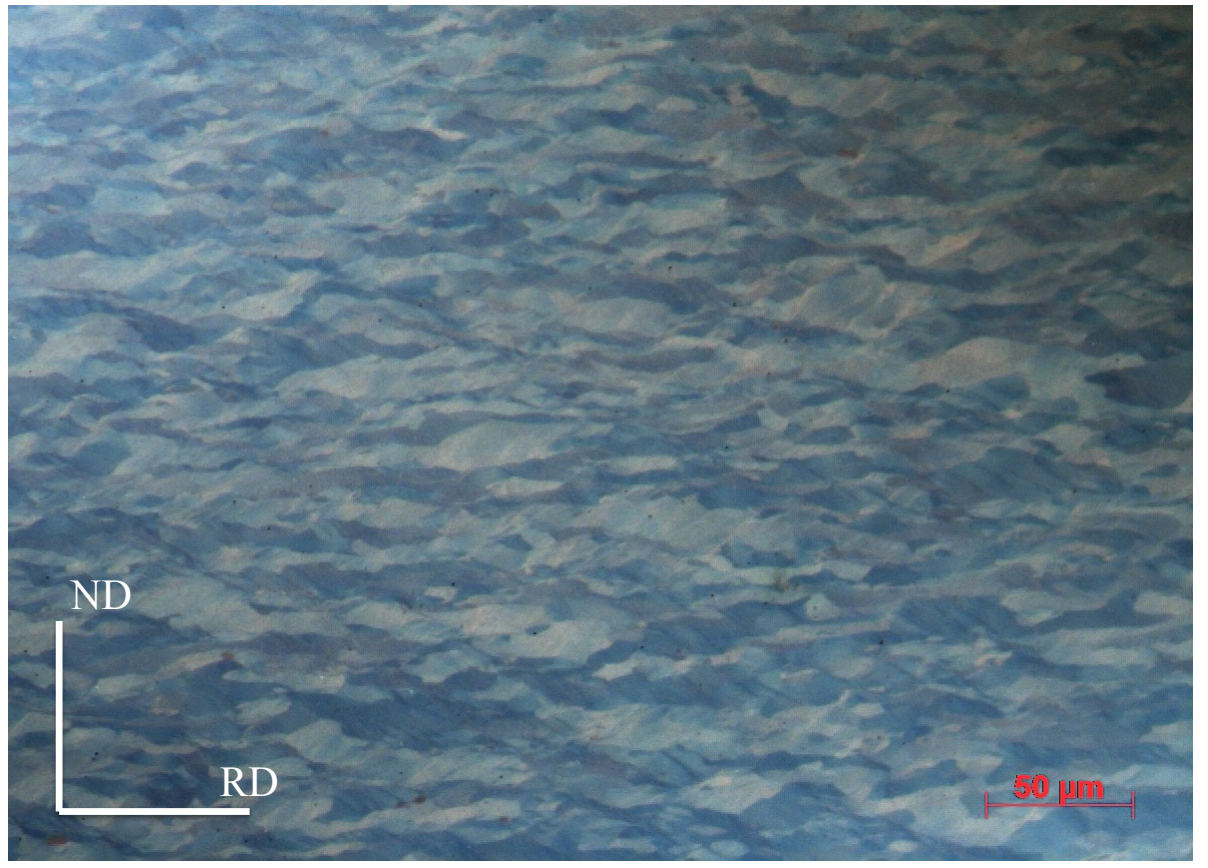

Fig. 1: Optical micrograph of cold-rolled Zircaloy-4

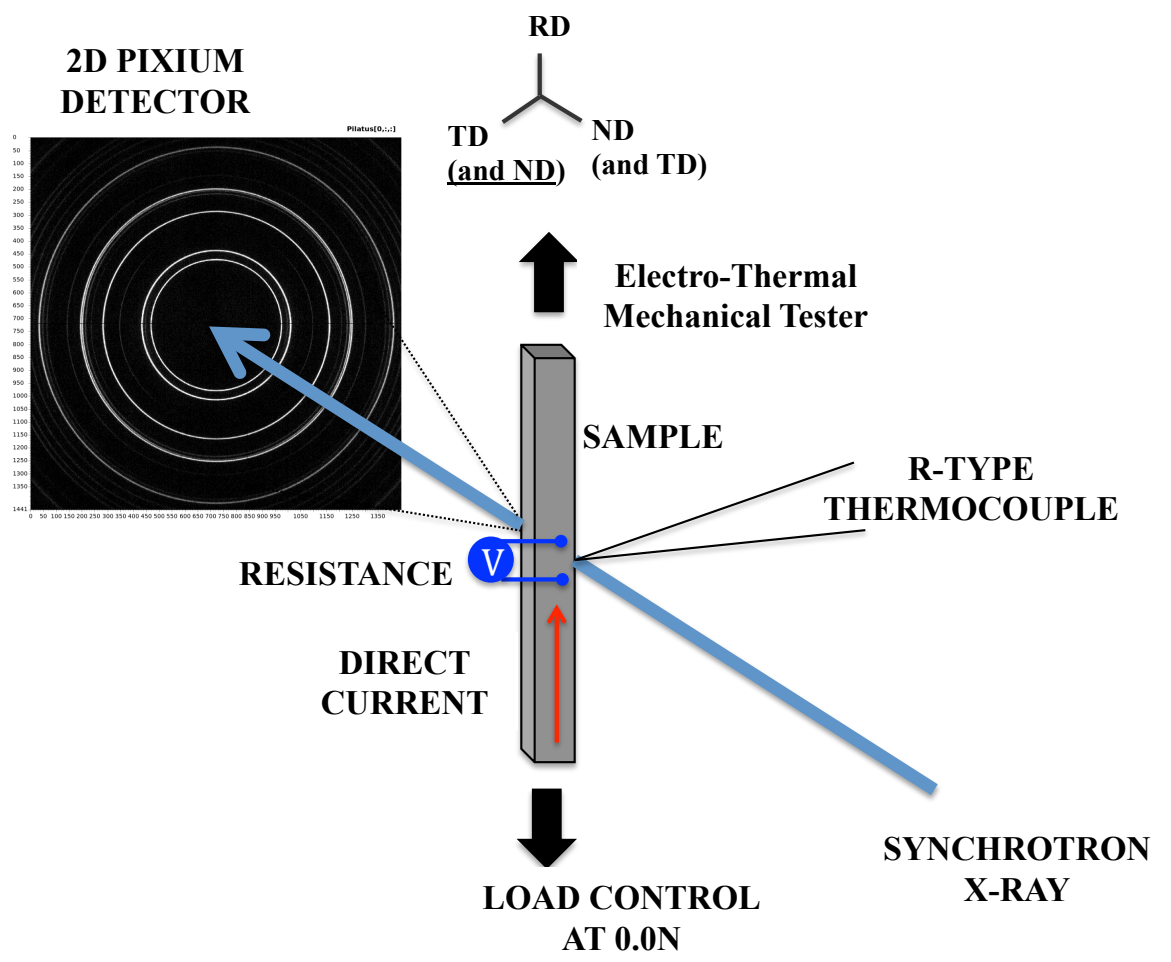

Fig. 2: High-energy synchrotron experimental setups with 2 directions of incident beam from normal direction (ND) and transverse direction (TD). 

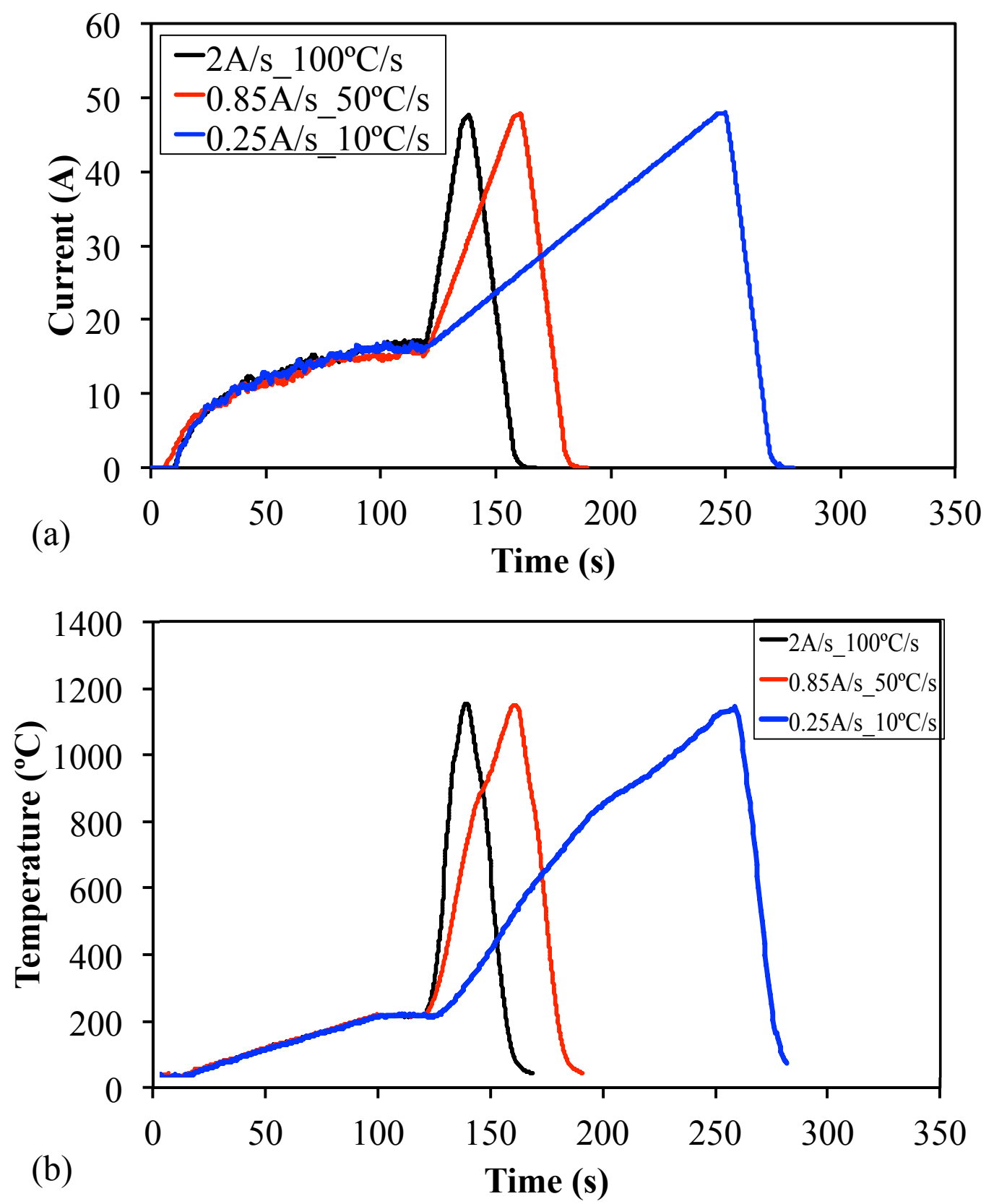

Fig. 3: Direct current controlled at constant rates of $0.25,0.85$ and $2 \mathrm{As}^{-1}$ by the ETMT to achieve the fast heating rates of 10,50 and $100^{\circ} \mathrm{Cs}^{-1}$ respectively on cold-rolled Zircaloy-4 samples of $16.0 \mathrm{~mm} \times 2.0 \mathrm{~mm} \times 0.67 \mathrm{~mm}$ dimension, after controlling temperature at $200^{\circ} \mathrm{C}$ at the same heating of $5^{\circ} \mathrm{Cs}^{-1}$. 

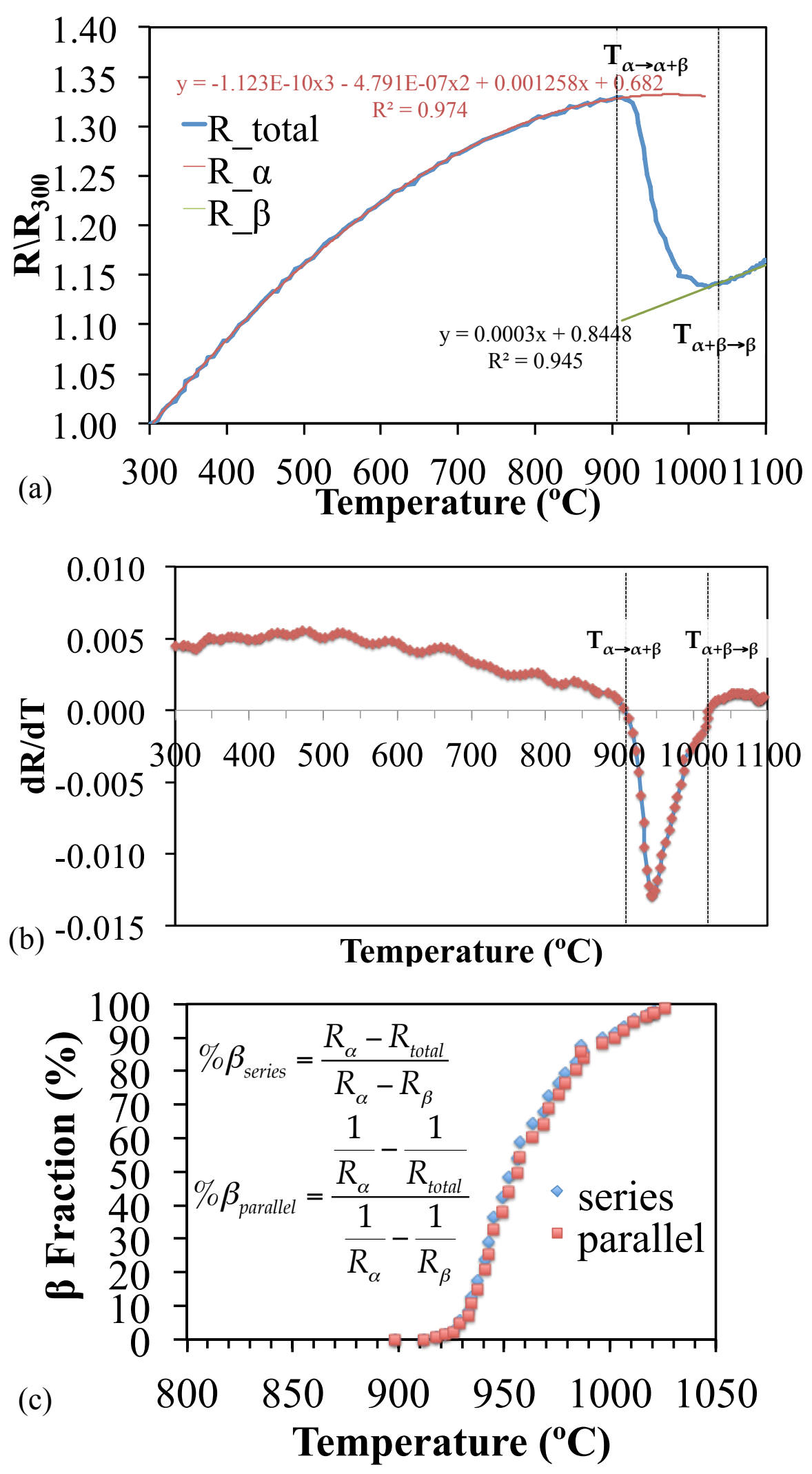

Fig. 4: (a) Measured normalized electrical resistance to that of $300^{\circ} \mathrm{C}$ at each temperature on a cold-rolled Zircaloy- 4 at $100^{\circ} \mathrm{Cs}^{-1}$ on an ETMT. (b) The first 
derivative of the normalized resistance to temperature. (c) $\beta$-fraction estimated by the two extreme cases of resistance [28].

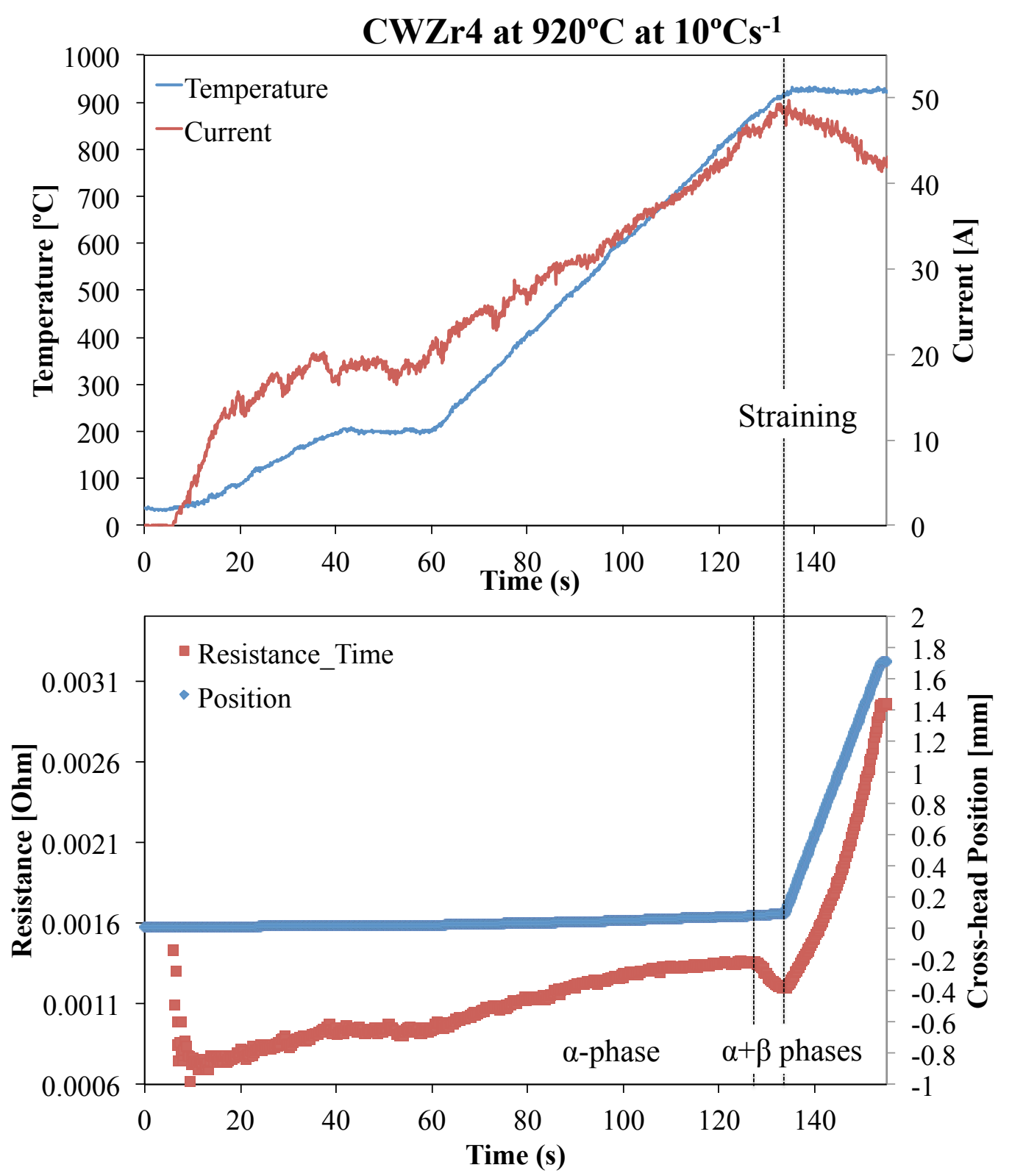

Fig. 5: (a) Evolution of sample temperature and direct current under temperature control at $10^{\circ} \mathrm{Cs}^{-1}$ up to $920^{\circ} \mathrm{C}$ before straining on an ETMT; (b) Evolution of electrical resistance under ETMT cross-head movements of $1.6 \mathrm{~mm}$ at the velocity of $0.16 \mathrm{mms}^{-1}$. 


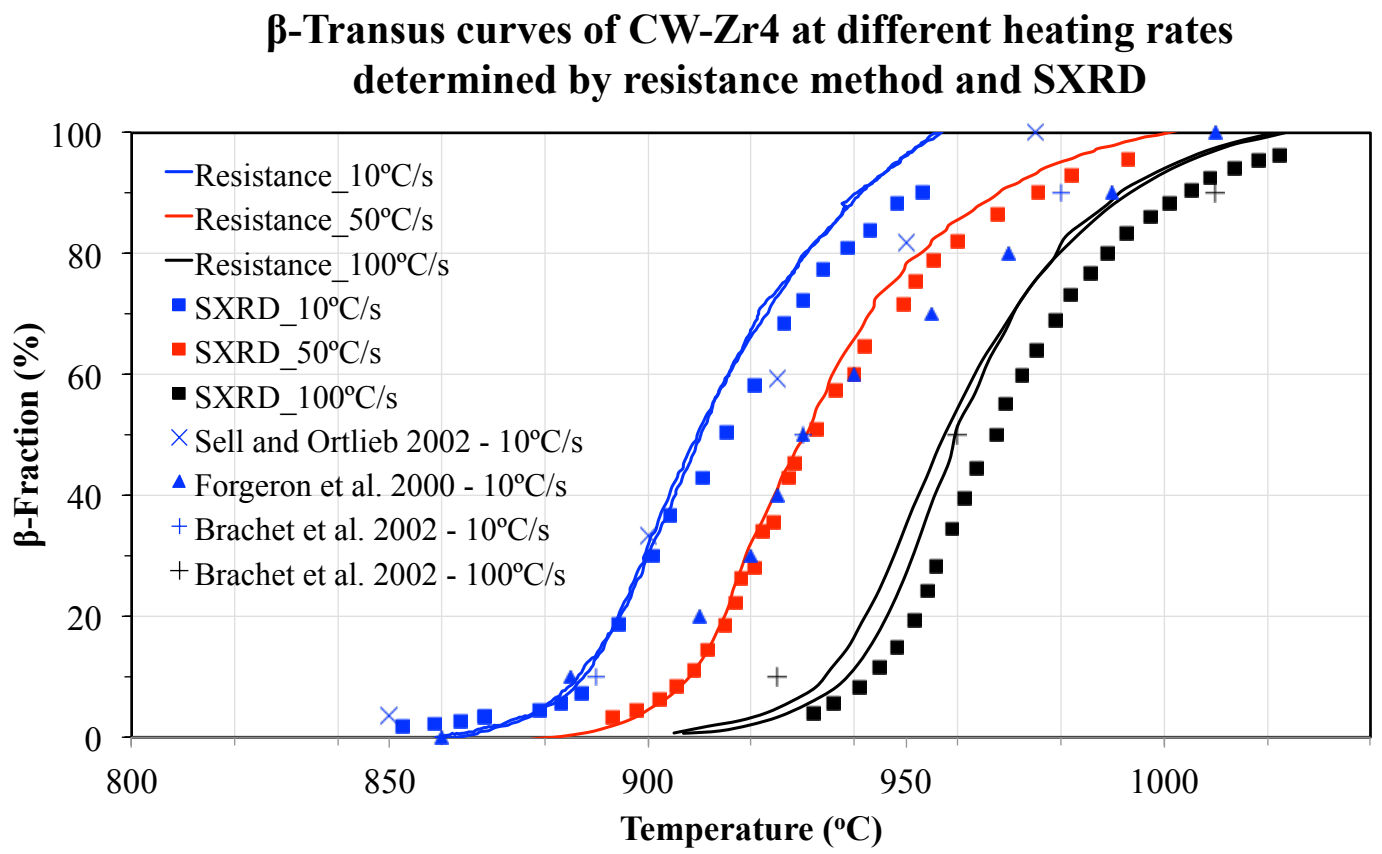

Fig. 6: $\beta$-approach curves of cold-rolled Zircaloy-4 at fast heating rates of 10, 50 and $100^{\circ} \mathrm{Cs}^{-1}$ measured by synchrotron x-ray diffraction (SXRD) and electrical resistance method on 2 samples each, showing less sampling variability. The $\beta$-fractions are compared to those of Zircaloy-4 in the literature at relevant heating rates $[5,6,9]$.
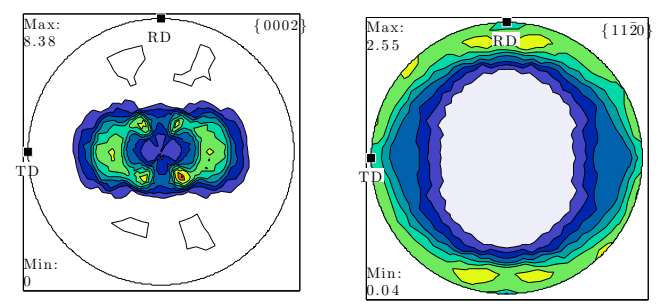

\section{Room Temperature}
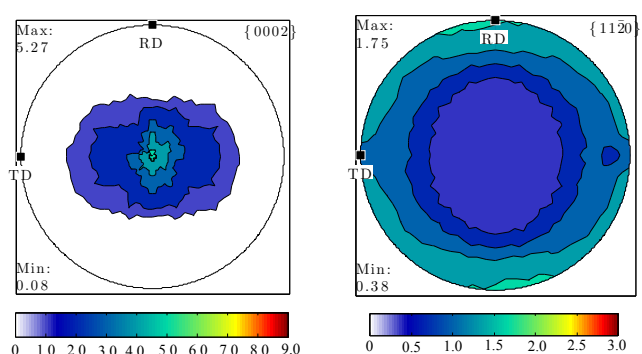

$\alpha$-phase

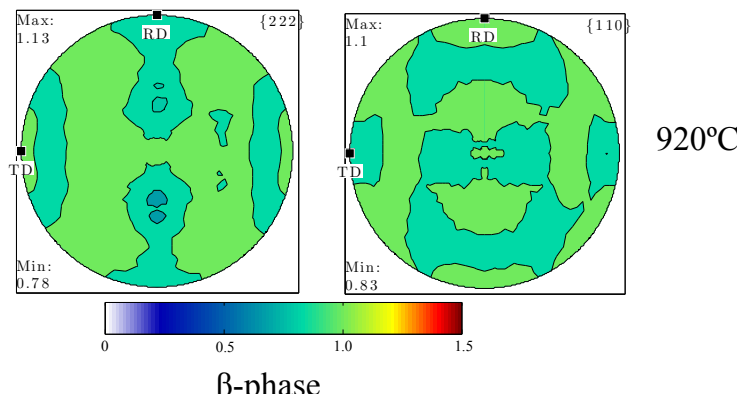

Fig. 7: Pole figures of cold-rolled Zircaloy-4 (a) at room temperature and (b) at $920^{\circ} \mathrm{C}$ at $10^{\circ} \mathrm{Cs}^{-1}-30 \% \beta$ measured by SXRD. 


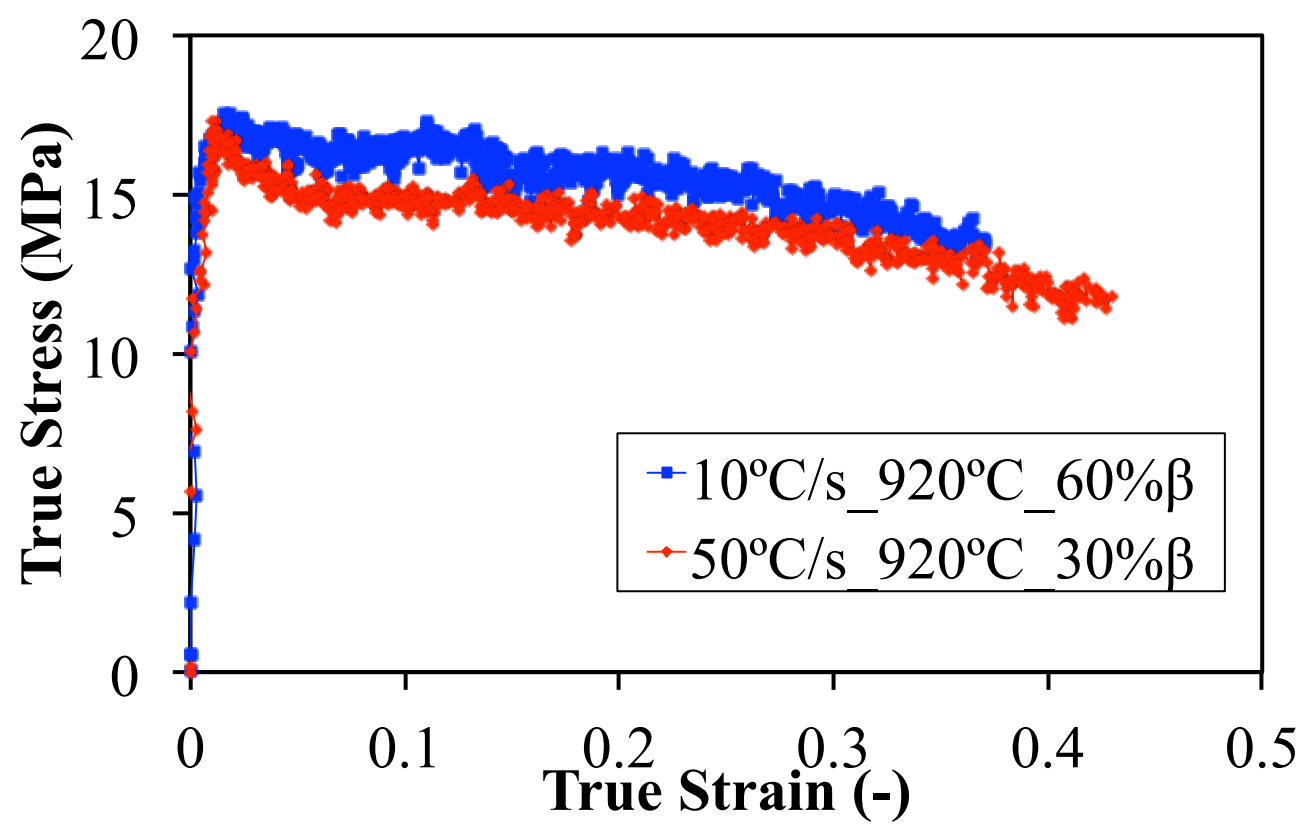

Fig. 8: Experimental flow stresses of cold-rolled Zircaloy-4 at $920^{\circ} \mathrm{C}$ at 10 and $50^{\circ} \mathrm{Cs}^{-}$ ${ }^{1}$ with ETMT cross-head expansion of $1.6 \mathrm{~mm}$ at the rate of $0.16 \mathrm{~mm} \mathrm{~s}^{-1}$, measured by electrical resistance. 

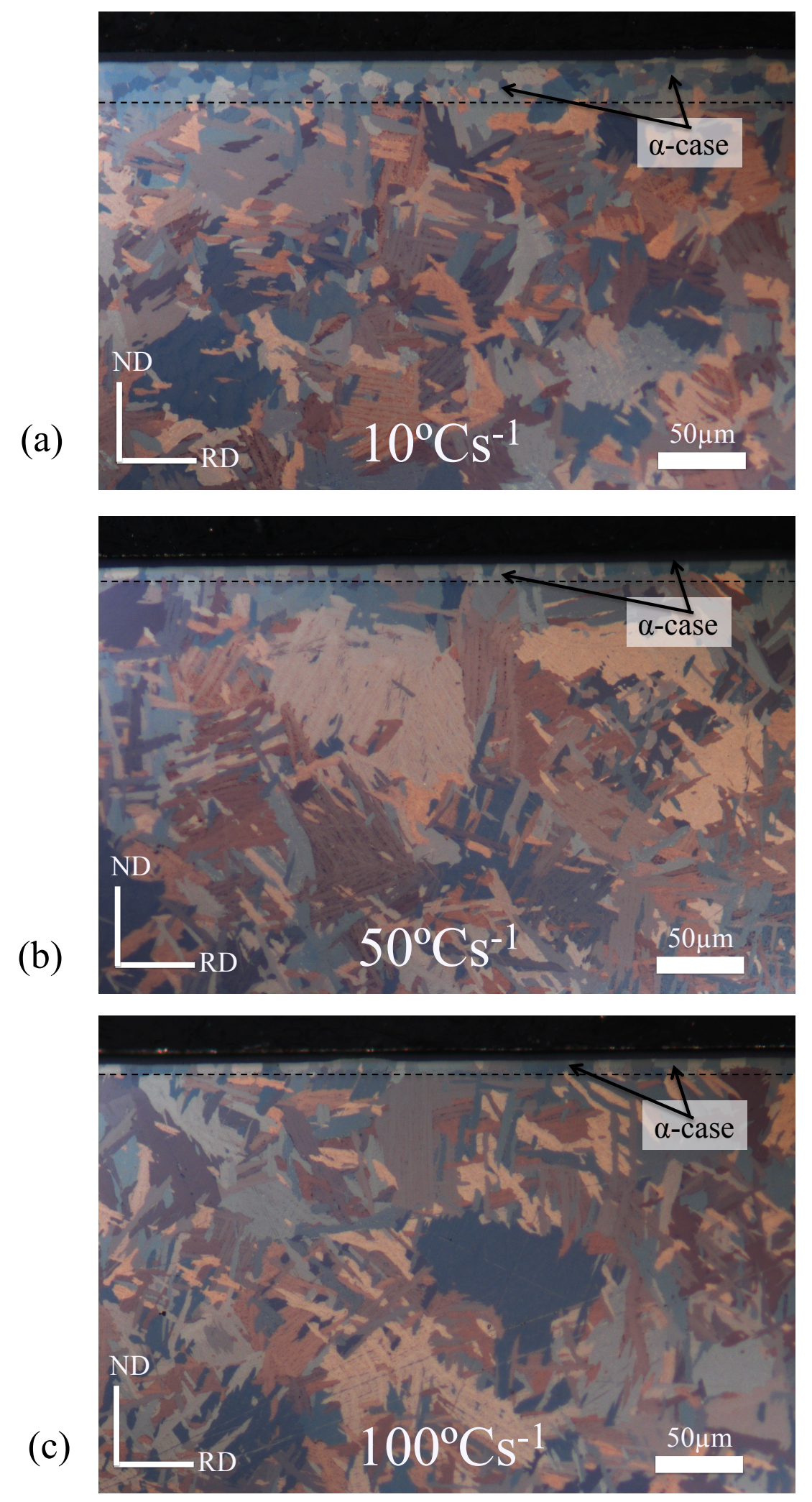

Fig. 9: Optical micrographs of cold-rolled Zircaloy-4 after the heating cycles at (a) $10^{\circ} \mathrm{Cs}^{-1}$, (b) $50^{\circ} \mathrm{Cs}^{-1}$ and (c) $100 \mathrm{Cs}^{-1}$, revealing more un-transformed $\alpha$-case due to oxygen uptake and oxidation at slower heating rates. 


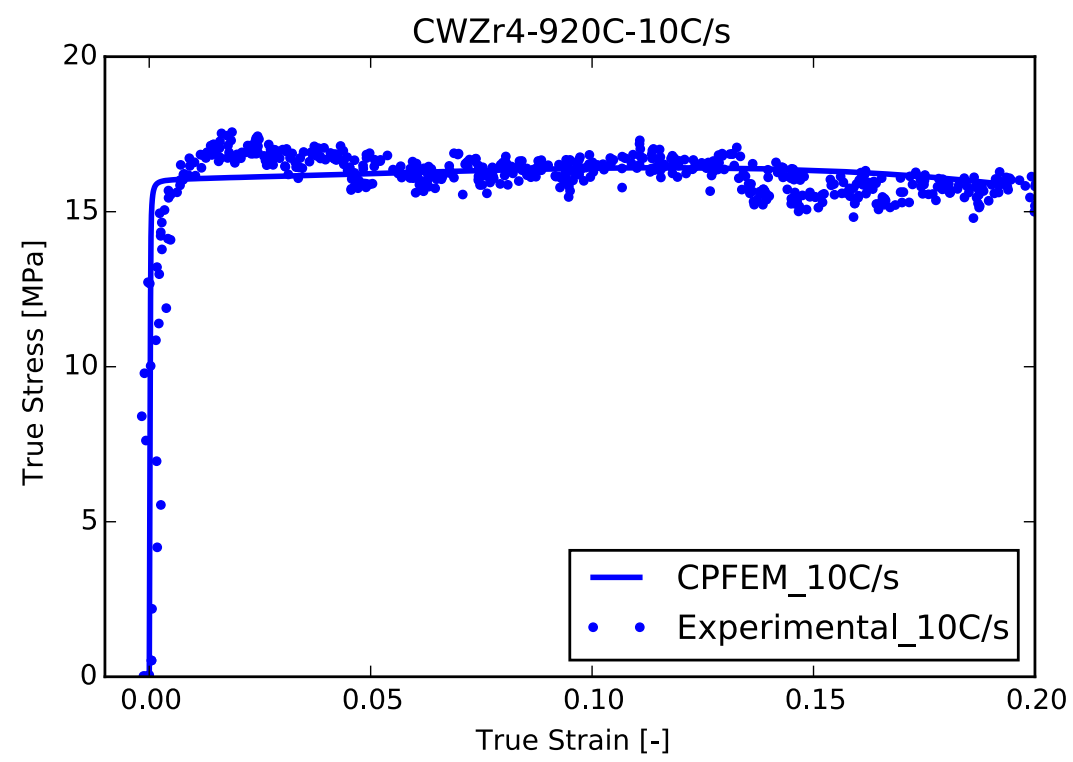

Fig. 10: Calibrated single crystal and hardening parameters for the CPFE model of cold-rolled Zircaloy-4 at $920^{\circ} \mathrm{C}$ at $10^{\circ} \mathrm{Cs}^{-1}$ by fitting experimental and predicted flow stresses which is taken into account the measured texture and phase fraction in this condition.

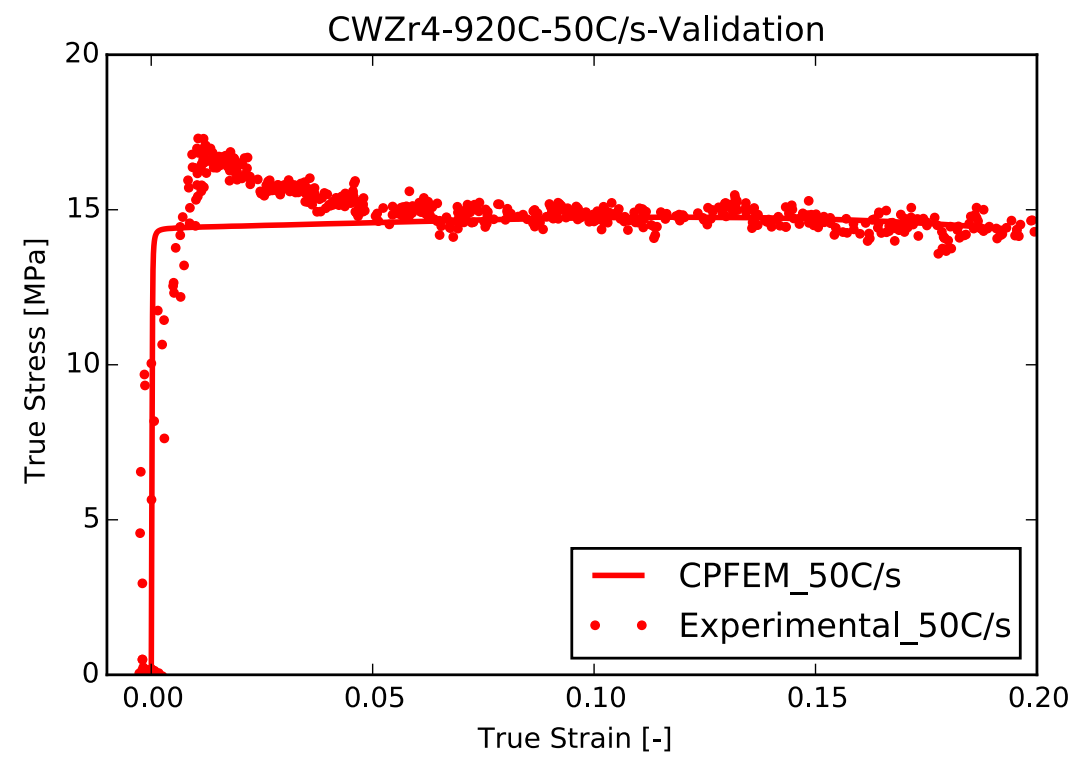

Fig 11: Comparison between the experimental macroscopic flow stress of cold-rolled Zircaloy-4 at $920^{\circ} \mathrm{C}$ at $50^{\circ} \mathrm{Cs}^{-1}$ and the predicted flow stress at the same temperature by CPFEM with measured phase fraction and texture by SXRD. 


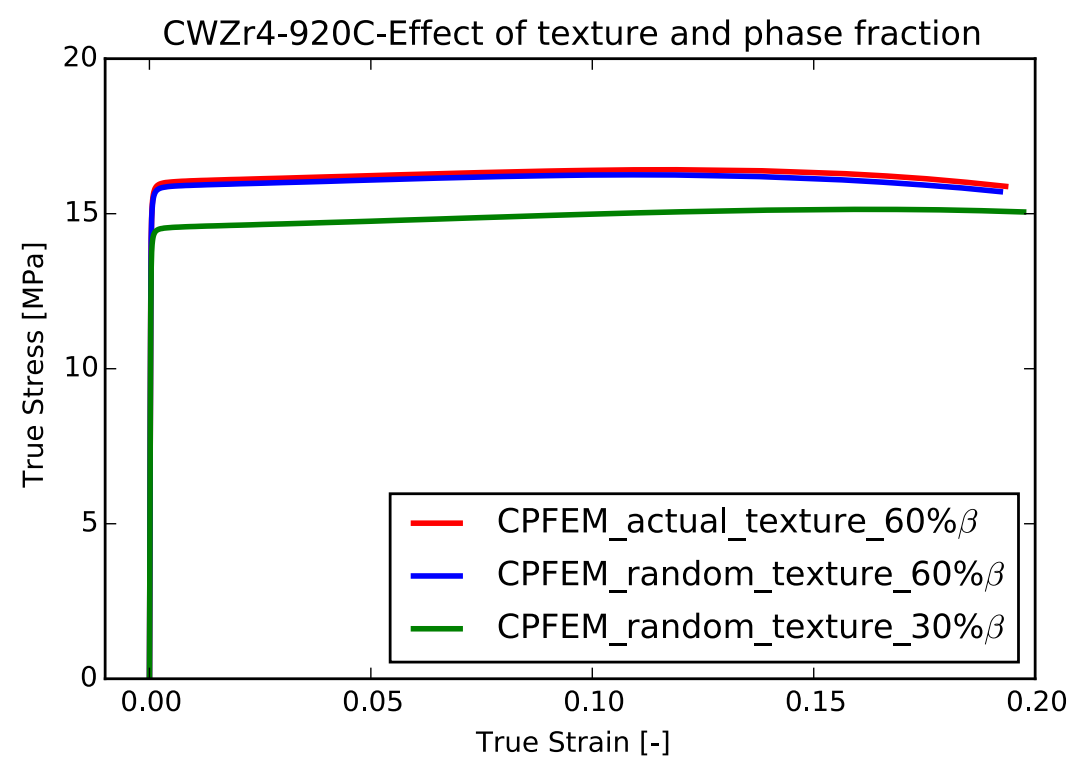

Fig. 12: Effect of phase fraction and texture on predicted flow stress of cold-rolled Zircaloy- 4 at $920^{\circ} \mathrm{C}$ by CPFEM.
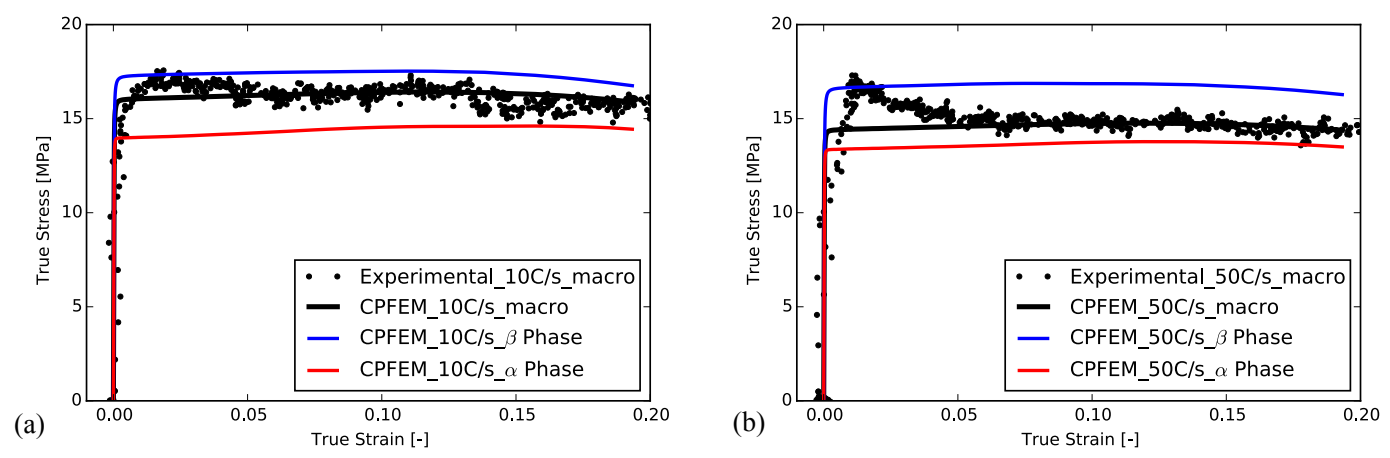

Fig. 13: Predicted flow stresses of each phase of cold-rolled Zircaloy- 4 at $920^{\circ} \mathrm{C}$ at the heating rate of (a) $10^{\circ} \mathrm{Cs}^{-1}-60 \% \beta$ and (b) $50^{\circ} \mathrm{Cs}^{-1}-30 \% \beta$. 